\title{
Chapter 8 \\ Health Inequality Monitoring: A Practical Application of Population Health Monitoring
}

\author{
Ahmad Reza Hosseinpoor and Nicole Bergen
}

\subsection{About This Chapter}

This chapter draws from contemporary examples to illustrate one application of population monitoring: health inequality monitoring. It demonstrates how monitoring of health inequalities has been integrated as a central part of population health initiatives across global and national contexts. The primary aims of the chapter are to demonstrate the importance of health inequality monitoring for equity-oriented policies, programmes and practices; provide examples of how all steps of the health inequality monitoring cycle have been applied; discuss practical challenges of monitoring health inequalities; and suggest strategies for strengthening health inequality monitoring.

The chapter begins by setting the scene, introducing health inequality monitoring, describing how health inequality monitoring is part of major global initiatives, and highlighting the benefits of institutionalizing health inequality monitoring as part of a national health information system. Next, building on the content presented in Chaps. 3, 4, 5, 6, and 7, the five-step cycle of health inequality monitoring is presented, covering (1) determining the scope of monitoring, (2) data collection, (3) analysing and interpreting the data, (4) reporting results and (5) knowledge translation. For each step of the cycle, a brief outline is provided of what the step entails

The authors alone are responsible for the views expressed in this publication, and they do not necessarily represent the views, decisions, or policies of their institutions.

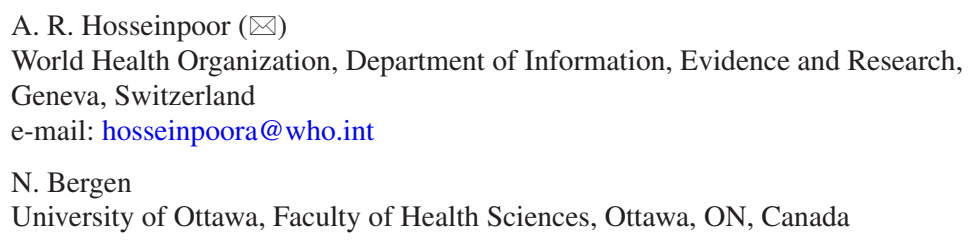


and examples of its application are given. Finally, some of the practical challenges of health inequality monitoring are reviewed, and forthcoming opportunities to strengthen the practice of health inequality monitoring are discussed. The chapter concludes by suggesting resources for further reading on contemporary applications of the cycle of health inequality monitoring.

\subsection{Setting the Scene}

In the past, most efforts to measure, understand and improve population health have focused on national averages. For example, ministries of health have collected data in order to quantify the national levels of infant morbidity and mortality in their country. The media have commonly reported on average disease rates in a country of interest and have speculated about why it may have increased or decreased over time. International organizations often have compared the average life expectancies across countries as a way to advocate for increased resources to improve the situation in poorly performing countries. While national averages provide valuable and necessary information about a population, they do not tell the whole story. They do not capture health inequalities that exist within a population.

Health inequality monitoring entails looking beyond national averages to understand how health is experienced differently by population subgroups. In other words, health inequality monitoring reveals which subgroups within a population perform well when it comes to health and which perform less well. In the example of infant health, across European countries, adverse infant outcomes and mortality were found to be elevated among babies born to migrant parents compared to babies born to parents who are not migrants (Andersen et al. 2016). The rate of cancer mortality in Spain was variable across different areas of the country, and even within cities, urban areas with high levels of socioeconomic deprivation were found to have excess cancer mortality compared to urban areas with lower socioeconomic deprivation (Puigpinos-Riera et al. 2011). Within OECD countries, those in the richest quintile tended to report a higher probability of seeing a specialist or a dentist than those in the poorest quintile, after adjusting for need (Devaux and de Looper 2012). With regard to life expectancy, in 21 OECD countries, 65-year-old men and women with a high level of education were found to live up to 4 years longer than their counterparts with a low level of education (Fig. 8.1) (OECD/EU 2016). By comparing health across population subgroups - which are defined by relevant socioeconomic, demographic or geographic characteristics - health inequality monitoring helps to deepen our understanding of how health is distributed within populations.

Increasingly, major global initiatives have recognized the importance of addressing health inequality (see Box 8.1). Alongside improvements in national average, faster improvements in health among disadvantaged population subgroups - a so-called narrowing of the gap - are emerging as a hallmark of success. Policies, programmes and practices that are specifically designed to improve health while simultaneously reducing health inequalities are said to be equity oriented. The final report of the 


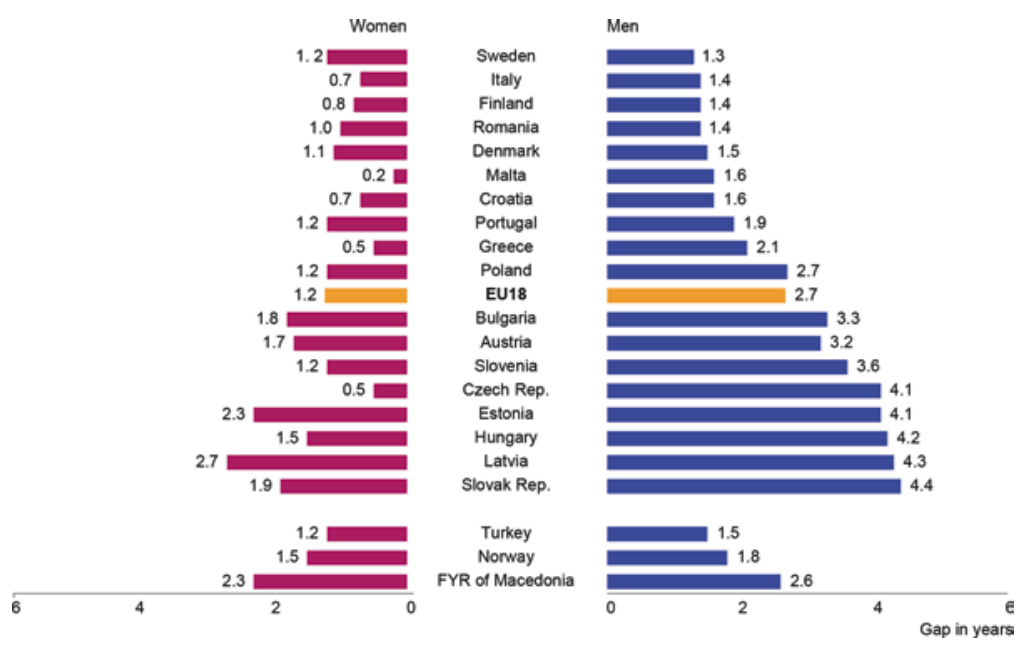

Fig. 8.1 Gap in life expectancy at age 65 by sex and educational level, 2013 (or nearest year). (Republished with permission of OECD Publishing, from OECD/EU. Health at a glance: Europe 2016 - State of health in the EU cycle. 2016. Paris: OECD Publishing; released under a Creative Commons Attribution 3.0 IGO License [CC BY 3.0 IGO]). Note: The figure shows the gap in expected years of life remaining at age 65 between adults with the highest level ("tertiary education") and the lowest level ("below upper secondary education") of education. (Source: Eurostat Database completed with OECD Health Statistics 2016 for Austria and Latvia)

\section{Box 8.1 From the Millennium Development Goals to the Sustainable Development Goals: Looking Beyond National Averages}

The United Nations Millennium Development Goals, which set targets for progress between 1990 and 2015, tracked changes in national averages. For instance, the goal pertaining to the reduction of child mortality called on countries to reduce, by two-thirds, the under-five mortality rate. Several countries made remarkable progress in improving national gains in health, which should not be understated. In some cases, however, certain population subgroups actually fell further behind - a trend which was masked by tracking national progress alone (World Health Organization 2015). The Sustainable Development Goals (2016-2030) have an explicit focus on the reduction of inequalities, including goals and targets that track progress among vulnerable population subgroups (United Nations General Assembly 2015).

Commission on the Social Determinants of Health provided a strong consensus that the global health community needed to take action to reduce health inequalities (Commission on Social Determinants of Health 2008). Subsequently, the United Nations 2030 Agenda for Sustainable Development (the '2030 SDG Agenda'), adopted in 2015, demonstrated a commitment to the reduction of inequality. This commitment is evident in its slogan: to 'leave no one behind' (United Nations General 
Assembly 2015). The Sustainable Development Goal (SDG) on health aims to ensure healthy lives and promote well-being for all at all ages and includes a call for the advancement of universal health coverage (UHC). The two core components of UHC are to extend the coverage of good-quality, essential health services and to ensure financial protection through reducing dependence on out-of-pocket payments for health services. The progressive realization of UHC means that progress in these two areas will be prioritized and accelerated among the most disadvantaged population subgroups (Hosseinpoor et al. 2014). Health inequality monitoring can indicate whether disadvantaged population subgroups are improving over time and thus help countries to track whether UHC is being realized progressively.

As discussed in Chap. 2, a main function of national health information systems is to produce intelligence about health that enables evidence-informed policy. Policies - as well as programmes and practices - that are equity oriented (such as UHC) should be informed by intelligence about the nature, magnitude and trends of health inequalities within the population. Health inequality monitoring contributes evidence to produce this intelligence. It helps to answer questions such as: Are there differences in health based on income level? Education level? Place of residence? Other important dimensions of inequality? Which of these differences are meaningful? Have health inequalities widened or narrowed over time? By identifying where health inequalities exist, health inequality monitoring can provide a base for further quantitative and qualitative research. Further research can explore the underlying factors that contribute to generating and perpetuating health inequality in a population and get a better grasp on why health inequality exists. A comprehensive and multifaceted understanding of health inequalities and their root causes is necessary to strengthen the equity orientation of policies, programmes and practices (WHO 2013, 2017d, 2018).

Health inequality monitoring should be institutionalized as a regular practice of national health information systems. What does it mean to institutionalize health inequality monitoring? National health information systems should collect data about health as well as data about diverse dimensions of inequality (income level, education, area of residence, sex/gender, age, etc.), and data collection should be done on a regular and ongoing basis. Additionally, national health information systems should have the technical capacity to analyse and report health inequality data. Resources should be allocated to maintaining and building upon these capacities. Institutionalizing health inequality monitoring also means that there are established mechanisms for knowledge translation; that is, there are regular opportunities to integrate the results of health inequality monitoring into policy decisions.

\subsection{Cycle of Health Inequality Monitoring}

The cycle of health inequality monitoring is one application of the population health monitoring cycle and can be broken down into five steps, which span from determining the scope of monitoring (step 1) through to informing policy (step 5) (see 


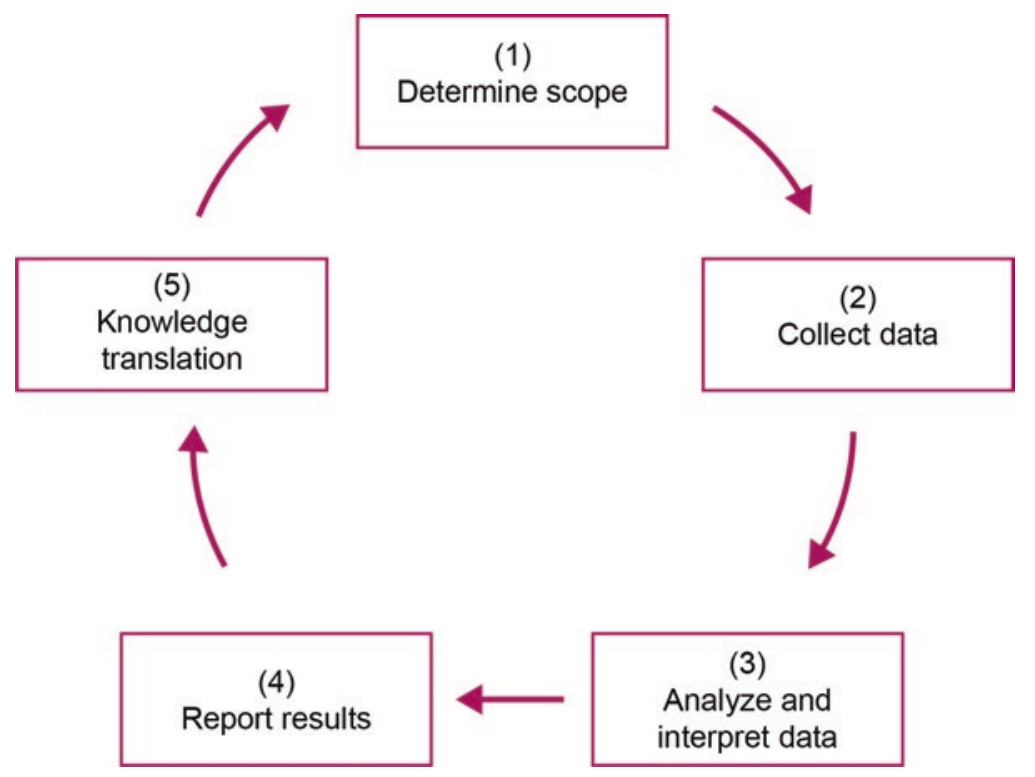

Fig. 8.2 The cycle of health inequality monitoring (adapted from (WHO 2013)). (Reproduced with permission of the World Health Organization; released under a Creative Commons Attribution 3.0 IGO License [CC BY 3.0 IGO])

the Introduction section and detailed discussions of each step in Chaps. 3, 4, 5, 6, and 7) (WHO 2013, 2017c.) Each of the five steps builds on the previous ones. Health inequality monitoring is portrayed as a cycle because, once the steps have all been completed and policy changes are implemented, there is a new need for monitoring to ensure that health inequalities continue to diminish. Even in cases where health inequality is already minimal, regular monitoring is important to ensure that health inequality remains low. Figure 8.2 summarizes the cycle.

\subsubsection{Step 1: Determine the Scope of Monitoring}

The first step of health inequality monitoring is to determine the scope of monitoring. As detailed in Chap. 3, the use of frameworks and models can help to identify key questions or information gaps that monitoring efforts can then address. Depending on the type of questions and information gaps that are identified, health inequality monitoring may have an expansive scope (e.g. encompassing multiple health topics, different aspects of the health sector and their intersection) or a narrow scope (e.g. focusing on a select number of health topics or even a single health topic). Like other types of population health monitoring, health inequality monitoring requires the selection of a set of relevant health indicators that aptly reflect the scope of monitoring. 
Health inequality monitoring also requires the selection of relevant dimensions of inequality, which serve as the basis for forming population subgroups. Dimensions of inequality may stem from any factor that constitutes a source of discrimination or social exclusion that is detrimental to health. The types of dimensions of inequality that can be applied in health inequality monitoring are vast, encompassing socioeconomic, demographic, geographic and other characteristics. Common socioeconomic dimensions of inequality include economic status/wealth, education level and deprivation; common demographic dimensions include sex and age; and common geographic dimensions include place of residence and subnational division (region, district, etc.). Other dimensions may include disability status, religion, migration status, aboriginal status, etc.

For every dimension of inequality, there are numerous ways in which subgroups might be constructed. In practice, however, decisions about how to conceptualize subgroups may need to consider the characteristics and availability of data and the monitoring context. For example, wealth indices based on household asset ownership are commonly used in low- and middle-income countries, where populationbased surveys collect data about these variables; high-income countries tend to conceptualize economic status according to income level. Deprivation indices are a common way to capture socioeconomic inequality at the small-area level, which typically derive from census indicators (see Box 8.2). Subnational geographic dimensions of inequality are highly dependent on the country context and may reflect regional divisions (provinces, states, districts, etc., which are usually indicated in all data sources) or divisions that correspond with the organization of the health system (health regions, facility catchment areas, etc., which are included in administrative/facility records).

\section{Box 8.2 Examples of Deprivation Indices}

- Various deprivation indices have been developed that combine several different types of socioeconomic characteristics (e.g. income, employment, housing, crime, education, access to services and living environment) by small-area geographical units (such as census tracts, electoral wards, postcode areas or municipalities) (Morris and Carstairs 1991; Carstairs 1995).

- The Carstairs index was developed by Carstairs and Morris in 1991 for use in Scotland. It combines four census indicators - male unemployment, household overcrowding, lack of car ownership and low social class which are split by postcode (Carstairs and Morris 1989).

- The Townsend index, developed by Townsend in the late 1980s is based on four variables: unemployment, lack of car ownership, lack of home ownership and household overcrowding. Data are typically derived from census indicators and applied to census tracts (or aggregated to higher area levels) (Townsend 1987). 
Globally, sets of health indicators with relevance to a particular health topic or topics have been defined to promote a systematic and comparable approach to monitoring (see Sect. 3.5 of Chap. 3). In some cases, common dimensions of inequality are also suggested, and approaches have been developed to standardize how they are measured. In general, global sets of health indicators and dimensions of inequality are usually proposed with the caveat that countries should also integrate additional, setting-specific measures that may be relevant in their jurisdiction, but not necessarily universally.

For the purpose of monitoring progress towards the 2030 SDG Agenda, 232 indicators for monitoring have been defined, with 27 indicators listed for the health goal (United Nations Statistics Division, 2018). The United Nations General Assembly has clearly stated the importance of considering cross-cutting dimensions of inequality:

Sustainable Development Goal indicators should be disaggregated, where relevant, by income, sex, age, race, ethnicity, migratory status, disability and geographic location, or other characteristics, in accordance with the Fundamental Principles of Official Statistics.

(United Nations General Assembly 2014)

In the case of UHC, the World Bank and the World Health Organization have developed a framework to guide monitoring efforts. The framework includes a summary measure for the coverage of essential health services, which is an index comprised of 16 tracer indicators. The 16 tracer indicators reflect the coverage of essential health services within four categories: reproductive, maternal, newborn and child health; infectious diseases; noncommunicable diseases; and service capacity and access (see Table 8.1) (Boerma et al. 2014; Hogan et al. 2018).

\subsubsection{Step 2: Collect Data}

After determining the scope for monitoring, the next step of health inequality monitoring is to collect data. Recall that two types of data are required for health inequality monitoring: data about health and data about relevant dimensions of inequality. These two streams of data are the cornerstone for health inequality monitoring, and national health information systems should collect diverse information that covers both types of data. If the data are obtained from different sources, there should be a way to link them together (e.g. through common personal identification numbers or small-area identifiers) (see Chap. 4). For example, a study of multi-morbidities in Scotland used postcodes as a way to link health data from personal medical records with information about socioeconomic status of the area (Barnett et al. 2012).

The major sources of data for population health monitoring, detailed in Chap. 4, are frequently used for health inequality monitoring. These include several types of health surveys (e.g. population health surveys) and (health) registers (e.g. administrative registers, registers on vital statistics, surveillance systems and censuses). Table 8.2 contains examples of these data sources as well as their strengths and limitations for health inequality monitoring. 
Table 8.1 Framework of tracer indicators to measure UHC service coverage (adapted from (WHO 2017d)). (Reproduced with permission of the World Health Organization; released under a Creative Commons Attribution 3.0 IGO License [CC BY 3.0 IGO])

\begin{tabular}{l|l}
\hline Category & Indicator area: indicator \\
\hline newroductive, maternal, & Family planning: demand satisfied with a modern method \\
among women aged $15-49$ years $(\%)$ \\
Pregnancy and delivery care: antenatal care - four or more \\
visits (\%) \\
Child immunization: 1-year-old children who have received \\
three doses of a vaccine containing diphtheria, tetanus and \\
pertussis (\%) \\
Child treatment: care-seeking behaviour for children with \\
suspected pneumonia (\%)
\end{tabular}

Global efforts to conduct health inequality monitoring across countries have benefited from the widespread data collection efforts of multi-country, population-wide household surveys such as the Demographic and Health Surveys (DHS); the Multiple Indicator Cluster Surveys (MICS); the Global Adult Tobacco Survey (GATS); the Survey of Health, Ageing and Retirement in Europe (SHARE); and the European Health Interview Survey (EHIS) (US Agency for International Development 2017; UNICEF 2017b; SHARE 2017; European Commission 2017; WHO 2017a). DHS and MICS, which operate in several low- and middle-income countries, use a standardized and rigorous approach to collect data at regular time intervals. As a result, reliable and comparable data about certain health topics such 
Table 8.2 Strengths and limitations of data sources used in health inequality monitoring (adapted from (WHO 2013)). (Reproduced with permission of the World Health Organization; released under a Creative Commons Attribution 3.0 IGO License [CC BY 3.0 IGO])

\begin{tabular}{|c|c|c|}
\hline $\begin{array}{l}\text { Data source type and } \\
\text { examples }\end{array}$ & Strengths & Limitations \\
\hline \multicolumn{3}{|l|}{ Health surveys } \\
\hline $\begin{array}{l}\text { Population household } \\
\text { survey } \\
\text { Examples: } \\
\text { Demographic and } \\
\text { Health Survey (DHS) } \\
\text { Multiple Indicator } \\
\text { Cluster Survey (MICS) } \\
\text { Global Adult Tobacco } \\
\text { Survey (GATS) } \\
\text { Survey of Health, } \\
\text { Ageing and Retirement } \\
\text { in Europe (SHARE) } \\
\text { European Health } \\
\text { Interview Survey } \\
\text { (EHIS) }\end{array}$ & $\begin{array}{l}\text { Often collect data on a specific } \\
\text { health topic as well as dimensions } \\
\text { of inequality } \\
\text { Usually repeated over time, } \\
\text { allowing for monitoring of time } \\
\text { trends } \\
\text { Conducted in multiple countries, } \\
\text { allowing for benchmarking } \\
\text { Data are representative for a } \\
\text { specific population (often national) }\end{array}$ & $\begin{array}{l}\text { Sampling and non-sampling } \\
\text { errors can be important } \\
\text { Survey may not be representative } \\
\text { of small subpopulations of } \\
\text { interest (so it cannot be used to } \\
\text { assess cross-district inequality) }\end{array}$ \\
\hline \multicolumn{3}{|l|}{ Health registers } \\
\hline $\begin{array}{l}\text { Administrative } \\
\text { registers } \\
\text { Examples: } \\
\text { Individual health } \\
\text { records } \\
\text { Service records } \\
\text { Resource records }\end{array}$ & $\begin{array}{l}\text { Data are readily and quickly } \\
\text { available } \\
\text { Can be used at lower administrative } \\
\text { levels (e.g. district level) and may } \\
\text { be useful for monitoring } \\
\text { inequalities between geographical } \\
\text { areas }\end{array}$ & $\begin{array}{l}\text { Data may be fragmented or of } \\
\text { poor quality } \\
\text { Often data cannot be linked to } \\
\text { other sources, limiting the ability } \\
\text { to disaggregate by diverse } \\
\text { dimensions of inequality } \\
\text { Data may not be representative of } \\
\text { the whole population }\end{array}$ \\
\hline $\begin{array}{l}\text { Registers on vital } \\
\text { statistics and civil } \\
\text { registration } \\
\text { Examples: } \\
\text { Birth and death } \\
\text { registries } \\
\text { Municipal records } \\
\text { (marital status, } \\
\text { ethnicity, etc.) }\end{array}$ & $\begin{array}{l}\text { Can be used to generate reliable } \\
\text { estimates for mortality rate, life } \\
\text { expectancy and sometimes } \\
\text { cause-of-death statistics } \\
\text { May contain identifiers that can be } \\
\text { linked to information on sex, } \\
\text { geographical region, occupation, } \\
\text { education }\end{array}$ & $\begin{array}{l}\text { Incomplete in most low- and } \\
\text { middle-income countries } \\
\text { Does not regularly include } \\
\text { information on dimensions of } \\
\text { inequality other than sex }\end{array}$ \\
\hline $\begin{array}{l}\text { Surveillance systems } \\
\text { Examples: } \\
\text { Demographic } \\
\text { surveillance } \\
\text { Disease registries } \\
\text { Sentinel surveillance }\end{array}$ & $\begin{array}{l}\text { Can provide detailed data on a } \\
\text { single condition or from selected } \\
\text { sites } \\
\text { Sentinel surveillance site data are } \\
\text { useful for correction of over- } \\
\text { reporting or under-reporting in } \\
\text { other sources }\end{array}$ & $\begin{array}{l}\text { Not always representative of } \\
\text { population } \\
\text { Some systems may collect little } \\
\text { information relevant dimensions } \\
\text { of inequality }\end{array}$ \\
\hline Censuses & $\begin{array}{l}\text { Data cover the entire population (or } \\
\text { nearly so), providing accurate } \\
\text { denominator counts for population } \\
\text { subgroups }\end{array}$ & $\begin{array}{l}\text { Contains only limited information } \\
\text { on health } \\
\text { Conducted infrequently (every } \\
10 \text { years in many countries) }\end{array}$ \\
\hline
\end{tabular}


as reproductive, maternal, newborn and child health $(\mathrm{RMNCH})$ are available across many low- and middle-income countries. GATS, a nationally representative household survey, enables countries to collect data about adult tobacco use and key tobacco control measures. Covering more than 120,000 individuals aged 50 years or more, SHARE collects data that capture health and socioeconomic status and social/ family networks. The EHIS is part of the European Commission's data collection activities to produce public health statistics in Europe. The EHIS includes those aged 15 years or older living in private households and covers four modules: health status, health-care utilization, health determinants and demographic/socioeconomic information (see Chap. 4 for more information on EHIS).

At the data collection step, the practice of health inequality monitoring may be aided by data source mapping. Data source mapping is an exercise that helps to assess data availability for health inequality monitoring through organizing and cataloguing the contents of existing data sources. The exercise involves preparing four connected tables. The first table lists the data sources available for a given jurisdiction, such as a country. The second table shows the dimensions of inequality data contained within each data source. The third table lists the health indicator data contained within each data source. In some cases, data sources may collect different types of data in different years; any such inconsistencies should be noted in the second and third tables. Finally, the fourth table integrates the information from the second and third tables, indicating the data sources that contain both health indicator and dimension of inequality data. This exercise can also be helpful in exposing gaps that indicate where additional data collection is required or where means for facilitating data links may be introduced. For detailed explanation and examples of how data source mapping has been applied for health inequality monitoring, refer to the Handbook on Health Inequality Monitoring: With a Special Focus on Low- and Middle-Income Countries (WHO 2013) and an article showcasing Indonesia (Hosseinpoor et al. 2018b).

\subsubsection{Step 3: Analyse and Interpret Data}

After data are collected, the next step of health inequality monitoring is to analyse and interpret the data. This step begins by preparing disaggregating data estimates, which demonstrate the level of health in each population subgroup. Disaggregated data may include the most recent available data, reflecting the current situation, or they may include data from two or more points in time, permitting consideration of changes over time. Examining disaggregated data is an important part of understanding the patterns of health inequality across population subgroups.

Figure 8.3 shows an example of disaggregated data for the coverage of three $\mathrm{RMNCH}$ indicators in Armenia. For each indicator, data are disaggregated by economic status (shown as quintiles) and by place of residence (shown as urban and rural); the figure displays data from surveys conducted at three time points (2000, 2005 and 2010). An exploration of the data reveals some interesting findings. The 


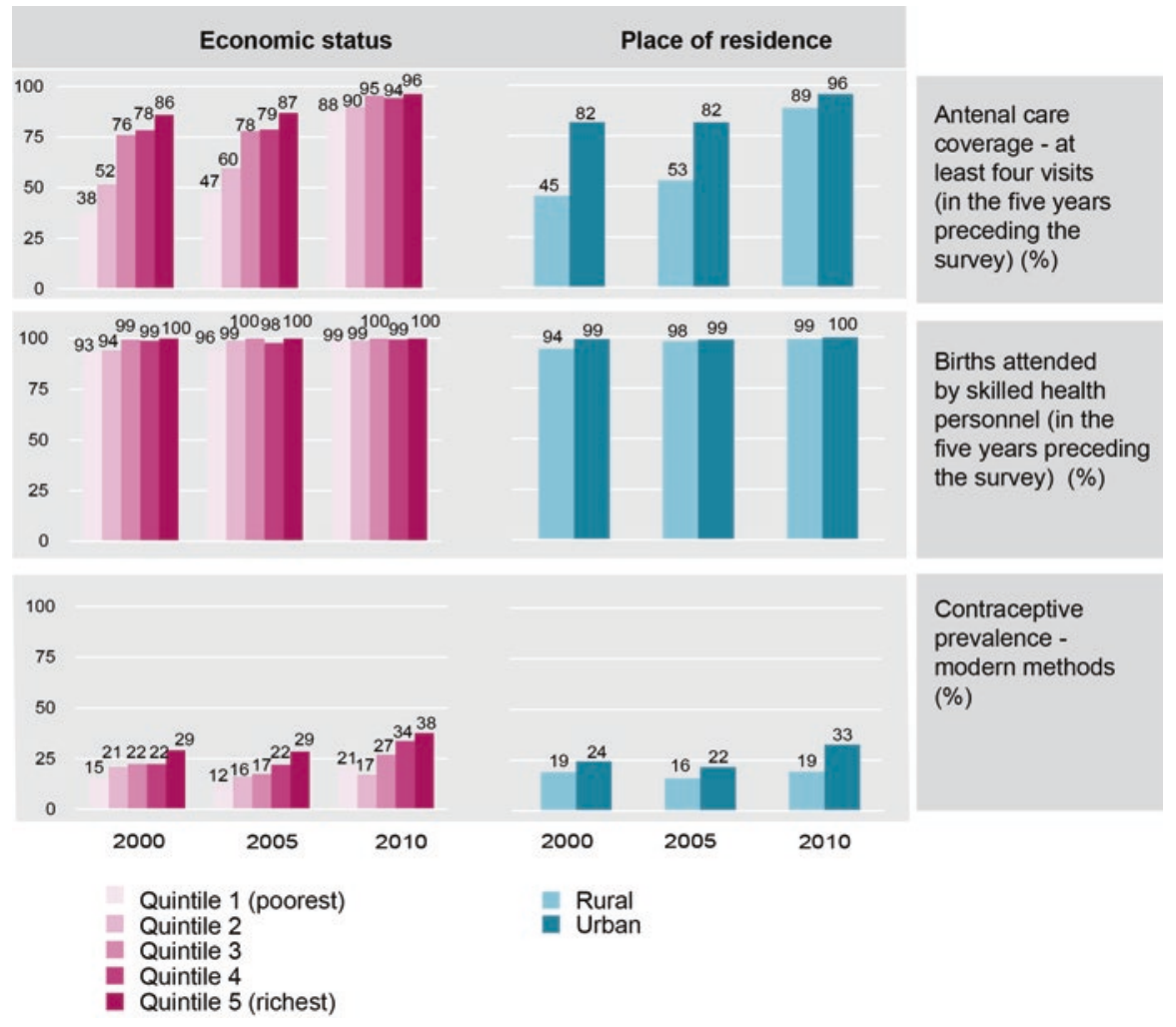

Fig. 8.3 RMNCH indicators in Armenia: coverage data disaggregated by economic status and place of residence (DHS 2000, 2005 and 2010). (Source: Health Equity Assessment Toolkit (HEAT): Software for exploring and comparing health inequalities in countries. Built-in database edition, Version 2. Geneva, World Health Organization, 2017. Data source: the disaggregated data used in this version were drawn from the WHO Health Equity Monitor database (2016 update))

coverage of antenatal care (at least four visits with a skilled or unskilled health provider) increased in all economic status subgroups between 2000 and 2010. In 2000 and 2005, the coverage level in quintiles 1 and 2 was much lower than the coverage level in quintiles 3, 4 and 5; however, between 2005 and 2010, the level of coverage increased substantially in the poorer quintiles, such that inequality narrowed. Similarly, the level of antenatal care coverage improved in urban and rural areas, with a narrowing of inequality over time. For both dimensions of inequality, the coverage of births attended by skilled health personnel in Armenia remained high, demonstrating low (or very minimal) levels of inequality, especially in 2005 and 2010. Disaggregated data for the contraceptive prevalence (modern methods) indicator by place of residence demonstrated a larger urban-rural gap in coverage in 2010 than in 2005, as the coverage in urban areas increased while the coverage in rural areas remained about the same. 
After inspecting patterns in disaggregated data, summary measures of inequality can be calculated. Summary measures of inequality yield a single number to reflect the level of inequality between two or more population subgroups. As the term suggests, they are a useful way to summarize the multiple points of disaggregated data. Different summary measures of inequality are appropriate for different applications. While certain summary measures of inequality are simple to calculate and intuitive to understand, others require advanced technical skills and/or data analysis software. Box 8.3 describes some of the common summary measures of inequality and their defining characteristics.

Two of the most straightforward types of summary measures of inequality are difference and ratio. Difference shows absolute inequality between two population subgroups. The difference in health service coverage by place of residence, for instance, can be calculated as the level of coverage in the urban area (\%) minus the level of coverage in the rural area $(\%)$, resulting in the difference (percentage

\section{Box 8.3 Defining Characteristics of Summary Measures}

Health inequality analyses can draw from a large number of different summary measures of inequality. Some of the important distinctions that characterize summary measures of inequality include:

- Summary measures express absolute or relative inequality. Absolute inequality measures reflect the magnitude of difference in health between population subgroups and retain the same unit of measure as the health indicator. Relative inequality measures show the proportional differences in health among subgroups and are unit-less.

- Summary measures may be described as simple or complex measures of health inequality. Simple measures of inequality make pairwise comparisons of health between two population subgroups (e.g. the most and least wealthy quintiles), whereas complex measures of inequality draw on data from all population subgroups (e.g. all five wealth quintiles) to produce a single number that expresses inequality.

- Complex summary measures may be applied to ordered or non-ordered dimensions of inequality. Ordered dimensions of inequality have an inherent positioning, and population subgroups can be logically ranked (e.g. wealth or education level). Non-ordered dimensions of inequality are not based on criteria that can be logically ranked (e.g. region or ethnicity).

- Summary measures may be weighted or unweighted. Weighted measures take into account the population size of each subgroup, whereas unweighted measures treat each population subgroup as if it were equally sized.

Table 8.3 shows the defining characteristics of some common summary measures of inequality. 
Table 8.3 Summary measures of inequality and associated characteristics. (Adapted from (WHO 2017b)). (Reproduced with permission of the World Health Organization; released under a Creative Commons Attribution 3.0 IGO License [CC BY 3.0 IGO])

\begin{tabular}{l|l|l|l|l}
\hline $\begin{array}{l}\text { Name of summary } \\
\text { measure }\end{array}$ & $\begin{array}{l}\text { Absolute } \\
\text { versus } \\
\text { relative }\end{array}$ & $\begin{array}{l}\text { Simple versus } \\
\text { complex } \\
\text { measure }\end{array}$ & $\begin{array}{l}\text { Ordered versus } \\
\text { non-ordered } \\
\text { complex measure }\end{array}$ & $\begin{array}{l}\text { Weighted versus } \\
\text { unweighted } \\
\text { measure }\end{array}$ \\
\hline $\begin{array}{l}\text { Absolute concentration } \\
\text { index }\end{array}$ & Absolute & Complex & Ordered & Weighted \\
\hline $\begin{array}{l}\text { Between-group } \\
\text { variance }\end{array}$ & Absolute & Complex & Non-ordered & Weighted \\
\hline Difference & Absolute & Simple & - & Unweighted \\
\hline Index of disparity & Relative & Complex & Non-ordered & Unweighted \\
\hline $\begin{array}{l}\text { Mean difference from } \\
\text { best performing } \\
\text { subgroup }\end{array}$ & Absolute & Complex & Non-ordered & Weighted \\
\hline $\begin{array}{l}\text { Mean difference from } \\
\text { mean }\end{array}$ & Absolute & Complex & Non-ordered & Weighted \\
\hline Mean log deviation & Relative & Complex & Non-ordered & Weighted \\
\hline $\begin{array}{l}\text { Population attributable } \\
\text { fraction }\end{array}$ & Relative & Complex & $\begin{array}{l}\text { Either ordered } \\
\text { or non-ordered }\end{array}$ & Weighted \\
\hline $\begin{array}{l}\text { Population attributable } \\
\text { risk }\end{array}$ & Absolute & Complex & $\begin{array}{l}\text { Either ordered } \\
\text { or non-ordered }\end{array}$ & Weighted \\
\hline Ratio & Relative & Simple & - & Unweighted \\
\hline $\begin{array}{l}\text { Relative concentration } \\
\text { index }\end{array}$ & Relative & Complex & Ordered & Weighted \\
\hline $\begin{array}{l}\text { Relative index of } \\
\text { inequality }\end{array}$ & Relative & Complex & Ordered & Weighted \\
\hline $\begin{array}{l}\text { Slope index of } \\
\text { inequality }\end{array}$ & Absolute & Complex & Ordered & Weighted \\
\hline Theil index & Relative & Complex & Non-ordered & Weighted \\
\hline
\end{tabular}

points). Ratio shows relative inequality between two population subgroups. The ratio in health service coverage by place of residence can be calculated as the level of coverage in the urban area (\%) divided by the level of coverage in the rural area $(\%)$, resulting in the ratio (unit-less). In the same manner, difference and ratio can be calculated between the level of coverage in the richest and poorest subgroups.

Drawing from the disaggregated data presented above, Fig. 8.4 displays the differences in coverage at each time point for the three indicators, and Fig. 8.5 shows the ratios. Here, it is apparent that the difference in antenatal care coverage between the richest and poorest subgroups remained elevated in both 2000 and 2005 (around 40-50 percentage points) and then decreased remarkably between 2005 and 2010 (to less than 10 percentage points). It is also apparent that the difference in coverage of births attended by skilled health personnel drops to less than 1 percentage point in 2005 (for place of residence) and 2010 (for economic status and place of residence). For contraceptive prevalence, the urban-rural difference is larger in 2010 than in 2005 and 2000. 


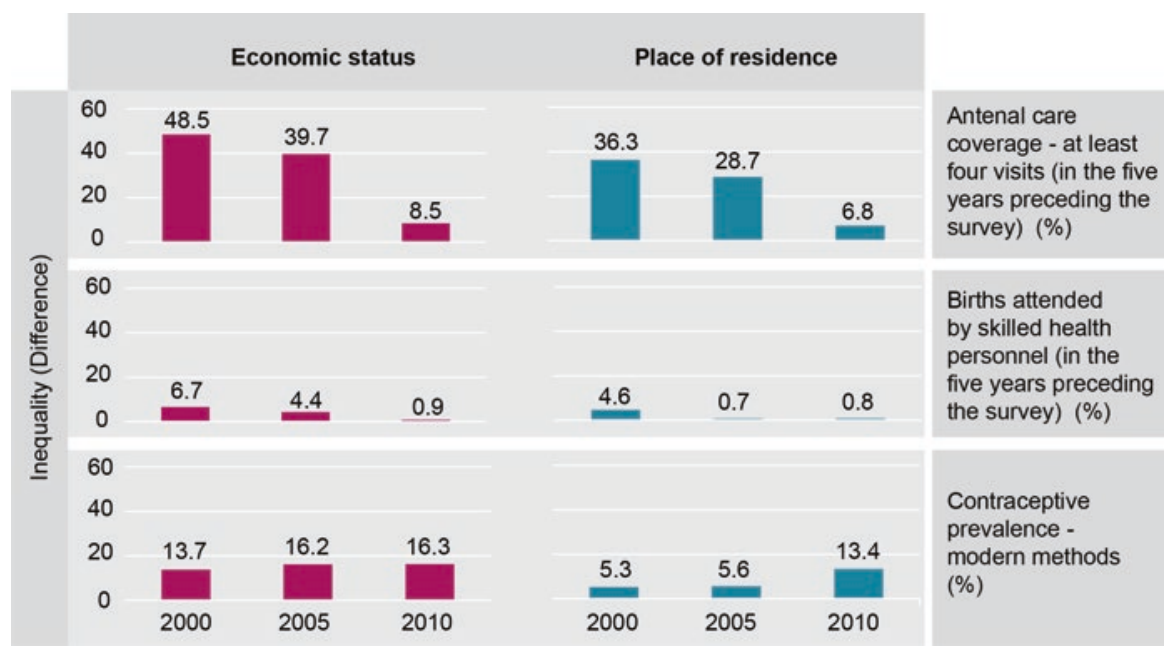

Fig. 8.4 RMNCH indicators in Armenia: difference in coverage by economic status (richestpoorest) and place of residence (urban-rural), in percentage points (DHS 2000, 2005 and 2010). (Source: Health Equity Assessment Toolkit (HEAT): Software for exploring and comparing health inequalities in countries. Built-in database edition, Version 2. Geneva, World Health Organization, 2017. Data source: the disaggregated data used in this version were drawn from the WHO Health Equity Monitor database (2016 update))

Overall, the same general patterns of increasing or decreasing inequality for these three RMNCH indicators tended to be the same when looking at the ratios (relative inequality, shown in Fig. 8.4) as indicated by the differences (absolute inequality). In the case of wealth-related inequality in contraceptive prevalence, however, absolute inequality increased slightly between 2000 and 2010, whereas relative inequality was about the same in 2000 and 2010. This demonstrates how absolute and relative inequality may not necessarily demonstrate changes in the same direction.

Simple summary measures like difference and ratio cannot take into account population shifts between subgroups over time. For instance, many countries face a situation where the percentage of the population with a low level of education is decreasing, and the percentage of the population with a high level of education is increasing. In these situations, weighted summary measures, such as the slope index of inequality (absolute measure) and the relative index of inequality (relative measure), can help to account for population shift and are interpreted like difference and ratio, respectively.

For more information about summary measures of inequality and their applications for assessing the change of within-country inequalities over time, refer to the Handbook of Health Inequality Monitoring: With a Special Focus on Low- and Middle-Income Countries (WHO 2013). 


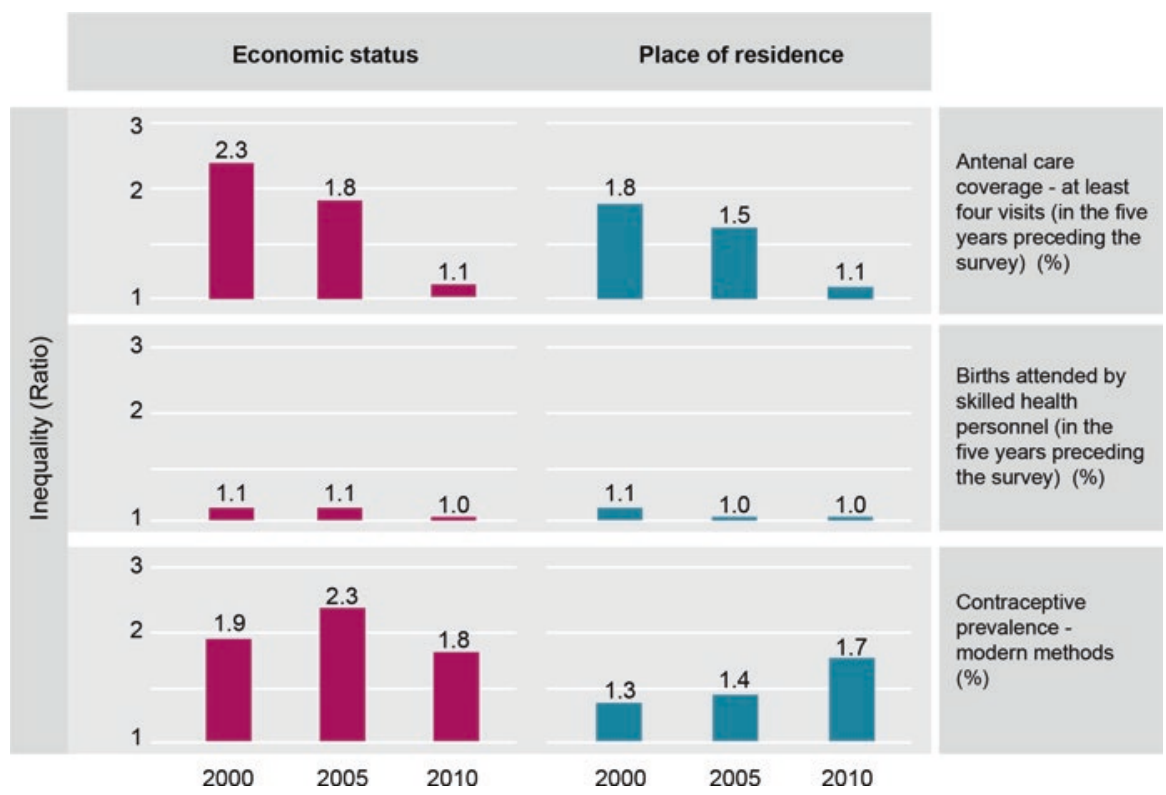

Fig. 8.5 RMNCH indicators in Armenia: ratio in coverage by economic status (richest/poorest) and place of residence (urban/rural) (DHS 2000, 2005 and 2010). (Source: Health Equity Assessment Toolkit (HEAT): Software for exploring and comparing health inequalities in countries. Built-in database edition, Version 2. Geneva, World Health Organization, 2017. Data source: the disaggregated data used in this version were drawn from the WHO Health Equity Monitor database (2016 update))

\subsubsection{Step 4: Report Results}

Reporting the results of health inequality monitoring follows the same basic tenets as other types of public health reporting. As outlined in Chap. 6, the general considerations within the three domains of public health reporting - content, production process and marketing - can be aptly applied to enhance reporting. When reporting the results of health inequality monitoring, however, certain special considerations arise. Reporting on health inequalities can quickly become complicated by the extensive nature of the underlying datasets: multiple health indicators disaggregated by various dimensions of inequality at several time points yield a lot of data! (The use of summary measures of inequality can be applied for a concise presentation of the data, though the characteristics of the measures should be taken into account see step 3.) In addition, the results of health inequality monitoring are often of interest to a wide range of diverse stakeholders across health and non-health sectors such as education, environment, agriculture, business and others. Stakeholders may have different levels of expertise and exposure to the health topics, data sources and analytical approaches that are applied in health inequality monitoring; diverse preferences and norms across stakeholder groups may affect how the results can be effectively marketed. 
The following approach to preparing reports of health inequality monitoring works through five sequential tasks, which highlight key decisions and action points that promote coherent, relevant and robust reporting. The application of this approach is illustrated using the WHO report State of Inequality: Childhood Immunization (WHO 2016b) ${ }^{1}$.

Task 1: Define the target audience and purpose of reporting. This includes determining the parameters that will guide the overall approach to reporting. It is important to consider the target audience's prior knowledge about health inequalities, as well as their level of technical expertise. For example, does the target audience have experience with complex summary measures of inequality and advanced statistics?

- The State of Inequality: Childhood Immunization report was developed for a broad audience with variable levels of experience in the area of health inequality monitoring. The primary target audience includes technical staff as well as public health professionals and researchers.

- The purpose of the State of Inequality: Childhood Immunization report is to serve 'as source of high-quality data for those involved in making policy decisions affecting health or those working to improve childhood immunization coverage'.

Task 2: Select the scope of reporting. Bearing in mind the target audience and the purpose of reporting, next determine which aspects of the state of inequality will be covered in the report. This includes assessing whether to report the latest status of inequality, the trends in inequality over time and/or benchmarking. The scope of reporting will also be influenced by the data availability.

- The scope of reporting in the State of Inequality: Childhood Immunization report stems from two overarching questions: What inequalities in childhood immunization coverage exist? And how have childhood immunization inequalities changed over the past 10 years?

- The report contains data from 69 countries and makes comparisons of the levels of within-country inequality (benchmarking). The best and worst performing countries are identified, and an extended analysis of poor performing countries is provided.

Task 3: Define the technical content of the report. Decisions about the content to report should be informed by a thorough exploration of the data and an assessment of the most salient conclusions that the data support (see Box 8.4). Generally, reports about health inequality should contain disaggregated data estimates. If simple and complex measures of inequality reflect the same conclusions, simple measures should be used, as they are more intuitive and easier to communicate and understand. In some cases, however, it may be appropriate to use complex measures of inequality.

- The content of the State of Inequality: Childhood Immunization report centres around four pertinent dimensions of inequality: household economic status, mother's education, place of residence and sex.

${ }^{1}$ The resource received first prize from the British Medical Association's Medical Book Awards 2017 in the category 'digital and online resources'. 
- The report contains disaggregated data and draws from two statistical measures median and interquartile range - to describe patterns in disaggregated data from study countries.

- In addition to disaggregated data, the latest situation is presented using two simple measures of inequality (difference and ratio) and one complex measure of inequality (population attributable risk); absolute excess change is a summary measure used to convey change over time.

Task 4: Decide what methods and tools will be used to present the data. After defining the technical content, identify the reporting approach. Consider how the report will use conventional reporting tools such as text, tables, figures and maps, and consider whether it is appropriate to incorporate other tools, such as interactive data visualization.

- The State of Inequality: Childhood Immunization report uses text, tables and figures to communicate the key messages.

- The report also interfaces with interactive visuals that permit further exploration of the data: all of the static figures in the text are also available as interactive visuals. Additional interactive visuals containing story points and reference tables are available. The interactive visuals are referenced throughout the report using QR codes and URLs to direct the audience to the online visuals.

Task 5: Adhere to the best practices of reporting health inequalities. As a final task, consider what the audience needs to know to fully understand the context of the results. The best practices of reporting health inequalities include reporting both absolute and relative inequality, indicating the national average, indicating the population share of the subgroups, flagging results that are based on low sample sizes (if results are based on surveys), reporting the statistical significance (if appropriate), and reporting the underlying methods and processes (WHO 2013, 2017c).

- The State of Inequality: Childhood Immunization report adheres to the best practices, as listed above. In the cases of flagging results that are based on low sample sizes and reporting statistical significance, these appear in tooltip (pop-up) boxes within the interactive visuals.

\section{Box 8.4 WHO Resources for Analysing and Reporting Data About Health Inequalities: HEAT and HEAT Plus (WHO 2017b; Hosseinpoor et al. 2016; Hosseinpoor et al. 2018c)}

The Health Equity Assessment Toolkit (HEAT), developed by the WHO, serves as an interactive application that allows users to explore inequality and make comparisons across countries. Focusing on RMNCH, HEAT uses an existing database of disaggregated data to calculate summary measures of inequality. Users can create customized visuals based on disaggregated data or summary measures. HEAT Plus has the added feature of allowing users to upload their own database. HEAT was recognized as "highly commended" in the British Medical Association's Medical Book Awards 2018 in the category 'digital and online resources'. 


\subsubsection{Step 5: Knowledge Translation}

The fifth step of the health inequality monitoring cycle involves knowledge translation, that is, promoting the uptake of monitoring results into the policymaking process. The process of knowledge translation is highly iterative and context specific. Chap. 7 discusses challenges in addressing the evidence-to-action gap and strategies to promote the use of evidence to inform public health policy. In the cycle of health inequality monitoring, the main goal of knowledge translation is for changes - typically in the realm of policies, programmes and practices - to be implemented that improve population health while reducing health inequalities.

Presenting straightforward, evidence-informed priority areas for action may be helpful to encourage the consideration of health inequality monitoring results by policymakers. The Handbook on Health Inequality Monitoring: With a Special Focus on Low- and Middle-Income Countries details one approach to identifying priority areas that involves applying a scoring system to the results of health inequality monitoring (WHO 2013). Briefly, each health indicator and dimension of inequality combination is assigned a score of 1,2 or 3 , based on the results of health inequality monitoring: 1 indicates that no immediate action is warranted; 2 indicates that action is warranted; and 3 indicates that urgent action is warranted. The national average for each indicator is also scored. Then, the average score for each health indicator is calculated to determine the priority areas across health indicators. Similarly, the average score for each dimension of inequality is calculated to determine priority areas across dimensions of inequality. While this approach overlooks important nuances and contextual aspects of policymaking, its simplicity and intuitiveness provide a concrete starting point for further consideration and discussion.

The WHO Innov8 Approach to Review National Health Programmes to Leave No One Behind details a systematic and comprehensive approach to integrating the results of health inequality monitoring into national health programmes (WHO 2016a). The Innov8 approach supports the commitment to progressive realization of universal health coverage and the right to health expressed in the Sustainable Development Goals. The Innov8 approach is an eight-step sequential review methodology that helps countries to enhance the equity orientation of the delivery and design of health programmes. Drawing from the results of health inequality monitoring, this approach guides multidisciplinary review teams through an extensive process yielding a better understanding of the causes of health inequities and identifying entry points in programmes to make them more equity-oriented, rights-based and gender-responsive as well as to address critical social determinants. Furthermore, the methodology encourages stakeholders to integrate measures to achieve sustained change and improved governance and accountability. The Innov8 approach can be adapted and applied in diverse settings and to different levels of governance. The eight steps of the Innov8 approach are outlined in Fig. 8.6.

Other tools, such as UNICEF's Equist, have been developed to encourage and facilitate the uptake of health inequality monitoring by policymakers (UNICEF 2017a). With a focus on RMNCH, Equist is an online platform that was designed to assist health policymakers and programme managers in strengthening health 


\begin{tabular}{|l|l|}
\hline 1 & Complete the diagnostic checklist \\
\hline 2 & Understand the programme theory \\
\hline 4 & Identify who is being left out by the programme \\
\hline 5 & Identify the barriers and facilitating factors that \\
subpopulations experience \\
6 & Consider intersectoral action and social participation \\
7 & Produce a redesign proposal to act on the review findings \\
8 & Strengthen monitoring and evaluation \\
\hline
\end{tabular}

Fig. 8.6 The Innov8 approach for reviewing national health programmes to leave no one behind (WHO 2016a). (Reproduced with permission of the World Health Organization; released under a Creative Commons Attribution 3.0 IGO License [CC BY 3.0 IGO])

systems. Equist provides stakeholders with access to the best available global evidence, data and tools and aims to help them devise strategies and approaches to reduce health inequalities.

\subsection{Practical Challenges}

Countries, or other jurisdictions where monitoring is carried out, experience unique sets of challenges along the five steps of health inequality monitoring. The challenges encountered depend partly upon the level of development of health information systems, as well as the capacity that exists to conduct monitoring, and the extent to which addressing health inequalities has been prioritized. Here, four common types of challenges are identified (Hosseinpoor et al. 2018a).

One type of challenge pertains to data collection and availability. Commonly, data are collected for health topics that are high profile and well-established on health agendas; data are often lacking for other topics that are less prominent or of emerging interest. Similarly, data about certain dimensions of inequality, such as place of residence, are routinely collected as part of health data sources. Certain others, such as socioeconomic dimensions, are mainly available through household health surveys. These dimensions may be gathered separately from health data and then linked to health data sources through individual or small-area identifiers. Obtaining recent and high-quality data may pose challenges.

Challenges may also stem from a lack of capacity to conduct analyses for health inequality monitoring. In some cases, individuals with the advanced technical knowledge to do health inequality analyses may not have access to the data or resources to do so. 
Health inequality monitoring necessitates specialized skills in effectively reporting and communicating the findings - an area of expertise that is distinct from doing analyses. It is too often taken for granted that strong analyses or compelling results will 'speak for themselves'. The importance of effective communication that is tailored to different target audiences should not be overlooked.

Finally, implementing changes based on the results of health inequality monitoring represents a considerable challenge. Health inequality is one of many considerations taken into account when planning policies, programmes and practices. Further, finding solutions to address health inequalities and their root causes often requires intersectoral action beyond the health sector alone. Planning and coordination across diverse groups of stakeholders is a necessary, but difficult, aspect of moving forward on understanding and addressing the root causes of health inequalities.

\subsection{Current and Future Developments}

Global health and development initiatives increasingly underscore the importance of monitoring and addressing health inequalities through evidence-informed policy. This includes a growing emphasis on the collection and use of disaggregated data. Globally, solutions to enhance the availability, quality and comparability of data across countries are emerging, driven in part by a growing emphasis on standardized analysis and reporting. While health inequality monitoring for some topics, such as RMNCH, is relatively well-established globally, other topics, such as noncommunicable diseases, are monitored less frequently, with fewer opportunities to make cross-national comparisons. Initiatives such as the Health Data Collaborative, comprised of multiple health partners across the globe, work with countries to enhance the availability, quality and use of data to track progress towards the healthrelated SDGs and promote evidence-informed policymaking for sustainable development (Health Data Collaborative 2017). Moving forward, the wide adoption of common indicator sets and the collection of high-quality data about those indicators will be key to generating evidence and spurring action on inequalities across a broader range of health topics.

Strengthening national health information systems, as detailed in Chap. 2 and in the 'Setting the Scene' section of this chapter, is central to overcome the challenges of health inequality monitoring. The WHO has developed a number of tools and resources for all countries, to support each step of the health inequality monitoring cycle (Hosseinpoor et al. 2015) (also see Box 8.4). Importantly, countries should invest resources in building capacity at each step of the health inequality monitoring cycle and should aim to establish the reduction of inequality as a common priority across sectors and levels of governance. The use of new technologies in how data are collected, linked, analysed and reported will continue to shape the practice of health inequality monitoring. The introduction of electronic records and the use of big data, for example, are two areas that pose exciting opportunities as emerging 
data sources. Analysis software and tools are increasingly available online and streamlined for a broader base of users that may not have advanced technical expertise. The growing availability of online interactive data visuals is shaping the norms around how results are communicated and making data accessible to wider audiences.

Acknowledgement The open access availability of this chapter was financially supported by the Dutch National Institute for Public Health and the Environment (RIVM). No funding for this work was received from WHO.

\section{Further Reading}

Hosseinpoor, A. R., Bergen, N., Schlotheuber, A., et al. (2016). Data resource profile: WHO Health Equity Monitor (HEM). International Journal of Epidemiology, 45, 1404-1405e.

Hosseinpoor, A. R., Bergen, N, Schlotheuber, A., \& Grove, J. (2018). Measuring health inequalities in the context of sustainable development goals. Bulletin of the World Health Organization, 96, 654-659. http://dx.doi.org/10.2471/BLT.18.210401.

WHO. (2013). Handbook on health inequality monitoring: With a special focus on low-and middleincome countries. Geneva: World Health Organization. Also available as an eLearning Module. WHO. (2016). State of inequality: Childhood immunization. Geneva: World Health Organization. WHO. (2017). National health inequality monitoring: A step-by-step manual. Geneva: World Health Organization.

WHO. (2018). Health Equity Monitor. (http://www.who.int/gho/health_equity/en/). Geneva: World Health Organization.

\section{References}

Andersen, A. M. N., Gundlund, A., \& Villadsen, S. F. (2016). Stillbirth and congenital anomalies in migrants in Europe. Best Practice \& Research. Clinical Obstetrics \& Gynaecology, 32, 50-59.

Barnett, K., Mercer, S. W., Norbury, M., Watt, G., Wyke, S., \& Guthrie, B. (2012). Epidemiology of multimorbidity and implications for health care, research, and medical education: A crosssectional study. The Lancet, 380, 37-43.

Boerma, T., AbouZahr, C., Evans, D., \& Evans, T. (2014). Monitoring intervention coverage in the context of universal health coverage. PLoS Medicine, 11, e1001728.

Carstairs, V. (1995). Deprivation indices: Their interpretation and use in relation to health. Journal of Epidemiology and Community Health, 49, S3-S8.

Carstairs, V., \& Morris, R. (1989). Deprivation: Explaining differences in mortality between Scotland and England and Wales. BMJ, 299, 886-889.

Commission on Social Determinants of Health. (2008). Closing the gap in a generation: Health equity through action on the social determinants of health: Final report of the commission on social determinants of health. http://apps.who.int/iris/bitstream/10665/43943/1/9789241563703_ eng.pdf. Accessed 4 Oct 2017.

Devaux, M., \& de Looper, M. (2012). Income-related inequalities in health service utilisation in 19 OECD countries, 2008-2009. OECD Publishing, Report no. 58. Paris: OECD Publishing. http://www.oecd-ilibrary.org/social-issues-migration-health/income-related-inequalities-inhealth-service-utilisation-in-19-oecd-countries-2008-2009_5k95xd6stnxt-en. Accessed 4 Oct 2017. 
European Commission. (2017). European Health Interview Survey (EHIS). http://ec.europa.eu/ eurostat/web/microdata/european-health-interview-survey. Accessed 20 Jul 2017.

Health Data Collaborative. (2017). https://www.healthdatacollaborative.org/. Accessed $20 \mathrm{Jul}$ 2017.

Hogan, D. R., Stevens, G. A., Hosseinpoor, A. R., \& Boerma, T. (2018). Monitoring universal health coverage within the Sustainable Development Goals: development and baseline data for an index of essential health services. The Lancet Global Health, 6(2), e152-e168. https://doi. org/10.1016/S2214-109X(17)30472-2.

Hosseinpoor, A. R., Bergen, N., Koller, T., Prasad, A., Schlotheuber, A., Valentine, N., et al. (2014). Equity-oriented monitoring in the context of universal health coverage. PLoS Medicine, 11, e1001727. https://doi.org/10.1371/journal.pmed.1001727.

Hosseinpoor, A. R., Bergen, N., \& Schlotheuber, A. (2015). Promoting health equity: WHO health inequality monitoring at global and national levels. Global Health Action, 8, 29034. https://doi. org/10.3402/gha.v8.29034.

Hosseinpoor, A. R., Nambiar, D., Schlotheuber, A., Reidpath, D., \& Ross, Z. (2016). Health Equity Assessment Toolkit (HEAT): Software for exploring and comparing health inequalities in countries. BMC Medical Research Methodology, 16, 141. https://doi.org/10.1186/ s12874-016-0229-9.

Hosseinpoor, A. R., Bergen, N., Schlotheuber, A., \& Boerma, T. (2018a). National health inequality monitoring: Current challenges and opportunities. Global Health Action, $11(\sup 1), 1392216$. https://doi.org/10.1080/16549716.2017.1392216.

Hosseinpoor, A. R., Nambiar D., Suparmi., \& Kusumawardani N. (2018b). Data source mapping: an essential step for health inequality monitoring. Global Health Action, 11(sup1), 1456743. https://doi.org/10.1080/16549716.2018.1456743.

Hosseinpoor, A. R., Schlotheuber, A., Nambiar, D., \& Ross. Z. (2018c). Health Equity Assessment Toolkit Plus (HEAT Plus): software for exploring and comparing health inequalities using uploaded datasets. Global Health Action,11(sup1), 1440783. https://doi.org/10.1080/165497 16.2018.1440783.

Morris, R., \& Carstairs, V. (1991). Which deprivation? A comparison of selected deprivation indexes. Journal of Public Health, 13, 318-326.

OECD/EU. (2016). Health at a glance: Europe 2016 - State of health in the EU cycle. Paris: OECD Publishing. http://www.oecd.org/health/health-at-a-glance-europe-23056088.htm. Accessed 4 Oct 2017.

Puigpinos-Riera, R., Mari-Dell'Olmo, M., Gotsens, M., Borrell, C., Serral, G., Ascaso, C., et al. (2011). Cancer mortality inequalities in urban areas: A Bayesian small area analysis in Spanish cities. International Journal of Health Geographics, 10, 6.

SHARE. (2017). SHARE - Survey of health, ageing and retirement in Europe. http://www.shareproject.org/. Accessed $20 \mathrm{Jul} 2017$.

Townsend, P. (1987). Deprivation. Journal of Social Policy, 16, 125-146.

UNICEF. (2017a). EQUIST: Equitable strategies to save lives. http://www.equist.info. Accessed $20 \mathrm{Jul} 2017$.

UNICEF. (2017b). Multiple Indicator Cluster Surveys. http://mics.unicef.org/. Accessed 20 Jul 2017.

United Nations General Assembly. (2014). General Assembly resolution 68/261 on 3-3-2014: Fundamental principles of official statistics. 68/261. https://unstats.un.org/unsd/dnss/gp/fundprinciples.aspx. Accessed 4 Oct 2017.

United Nations General Assembly. (2015). Transforming our world: The 2030 agenda for sustainable development. 2015;A/RES/70/1. https://sustainabledevelopment.un.org/post2015/transformingourworld. Accessed 4 Oct 2017.

United Nations Statistics Division. (2018). SDG Indicators: Global indicator framework for the Sustainable Development Goals and targets of the 2030 Agenda for Sustainable Development. https://unstats.un.org/sdgs/indicators/indicators-list/ Accessed 10 Oct 2018. 
US Agency for International Development. (2017). The Demographic and Health Surveys Program. http://dhsprogram.com/. Accessed 4 Oct 2017.

WHO. (2013). Handbook on health inequality monitoring: With a special focus on low-and middle-income countries. Geneva: World Health Organization. http://apps.who.int/iris/bitstr eam/10665/85345/1/9789241548632_eng.pdf?ua=1. Accessed 2 Sept 2017.

WHO. (2015). Health in 2015: From MDGs, Millennium Development Goals to SDGs, Sustainable Development Goals. Geneva: World Health Organization. http://www.who.int/gho/publications/mdgs-sdgs/en/. Accessed 4 Oct 2017.

WHO. (2016a). Innov8 approach for reviewing national health programmes to leave no one behind: Technical handbook. Geneva: World Health Organization. http://www.who.int/lifecourse/publications/innov8-technical-handbook/en/. Accessed 2 Sept 2017.

WHO. (2016b). State of inequality: Childhood immunization. Geneva: World Health Organization. http://www.who.int/gho/health_equity/report_2016_immunization/en/. Accessed 4 Oct 2017.

WHO. (2017a). Global Adult Tobacco Survey (GATS). Geneva: World Health Organization. http:// www.who.int/tobacco/surveillance/survey/gats/en/. Accessed 4 Oct 2017.

WHO. (2017b). Health Equity Assessment Toolkit (HEAT): Software for exploring and comparing health inequalities in countries. Built-in database edition. Version 2.0. Geneva: World Health Organization. http://www.who.int/gho/health_equity/heat_technical_notes.pdf?ua=1. Accessed: 20 Jul 2017.

WHO. (2017c). National health inequality monitoring: A step-by-step manual. Geneva: World Health Organization. http://apps.who.int/iris/handle/10665/255652. Accessed 4 Oct 2017.

WHO. (2017d). World Health Statistics 2017: Monitoring health for the SDGs. Geneva: World Health Organization. http://www.who.int/gho/publications/world_health_statistics/2017/en/. Accessed 4 Oct 2017.

WHO. (2018). Explorations of inequality: childhood immunization. Geneva: World Health Organization. http://www.who.int/gho/health_equity/report_2018_immunization/en/. Accessed 7 Oct 2018.

Open Access This chapter is licensed under the terms of the Creative Commons Attribution 3.0 IGO License (https://creativecommons.org/licenses/by/3.0/igo/), which permits use, sharing, adaptation, distribution and reproduction in any medium or format, as long as you give appropriate credit to International Organization and the source, a link is provided to the Creative Commons license and indicate if changes were made.

The images or other third party material in this chapter are included in the chapter's Creative Commons license, unless indicated otherwise in a credit line to the material. If material is not included in the chapter's Creative Commons license and your intended use is not permitted by statutory regulation or exceeds the permitted use, you will need to obtain permission directly from the copyright holder.

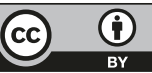

